\title{
J
}

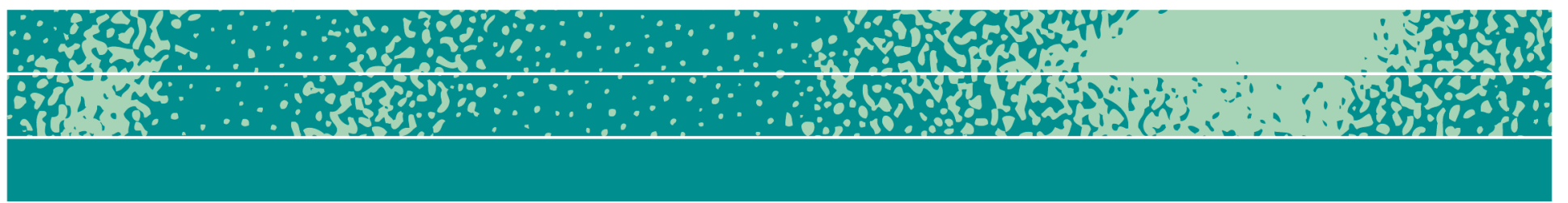

\section{The Future Airport - Experiments and Innovative Technologies}

\author{
Helene Ilkjaer
}

\begin{abstract}
Zooming in on the micro-processes involved in developing and user testing new technologies for airports, this article works with the notion of experiments as a way to understand iterative practices and future (re)orientations. In doing so, I aim to think through experiences and experiments with applied anthropology and corporate ethnography within a dialogic framework of 1) current airport industry efforts of revisioning stakeholder collaboration and airport re-branding and 2) the attempts of a Danish start-up company to create market disruption through innovative technology development. Although the experiments take place at different scales and are performed in different ways, I contend that they must be considered within a common frame in order to tease out their interconnectedness, particularly with regards to experimental confines and motivations. Based on some relatively raw case material, this article unfolds the different layers of experiments and the underlying assumptions that they make apparent.
\end{abstract}

\section{Key words}

Experimentation, User Tests, Airports, Technology
Page 1 of 22

JBA 8(1): 86-107 Spring 2019

(C) The Author(s) 2019 ISSN 2245-4217

www.cbs.dk/jba 


\section{Introduction}

As a qualitative consultant with a small Danish start-up company, I became part of a project team comprising engineers, physicists and designers. This work required a challenging shift from the habitual position as an anthropological observer to one in which I was an engaged team participant (cf. Rabinow 2014a, Sedgwick 2017). Inspired by recent anthropological work that explores collaboration and experimental modes of inquiry (cf. Leach 2014, Marcus 2014, Marres 2012, Rabinow 2014b, Wilkie 2014), I take up the notion of experiment to think through my experiences. As I struggled to make sense of, indeed come to terms with, my unaccustomed role and the constantly shifting business context it gradually dawned on me that I was perhaps not the only one experimenting my way in uncertain and unfamiliar terrain. I thus suggest that the notion of experiment is helpful for understanding the work practices and conditions in the company in particular and the airport industry more generally.

What is an experiment? Epistemologically, there is a division between those who view experiments as controlled acts undertaken in contained set-ups or labs with outcomes that are verifiable through exact replication. Others understand experiments to be explorative endeavors, non-linear processes of searching and trying out that are characterized by uncertainty, open-endedness and unexpectedness. It is in this latter understanding that I use the term experiment.

Hans-Jörg Rheinberger whose research explores the history and epistemology of experimentation particularly in the life sciences underlines the centrality of reorientations and he argues for longitudinal perspectives on experiments. Rheinberger reminds us that the bulk of experiments do not lead anywhere if considered individually: "They do not lead to promising findings, but they also do not lead to the clear-cut falsification of sharply delineated assumptions. They simply do not amount to anything that could be worth reporting. And yet these efforts enrich the experimental experience and therefore are integral to the experimental approach" (Rheinberger 2009:76). Experiments are thus ongoing learning processes, exploratory modes of inquiry and knowledge production, rather than (just) events or sites serving to verify or falsify hypothesizes and theories. This relocation of the experimental "from knowledge-site to knowledge-process" has occurred from the 1970's, writes Alberto Corsín Jiménez in his outline of the genealogy of experiments in the sciences (Corsín Jiménez 2014:386). However, while the experimental has proliferated as a modus operandi in general, Corsín Jiménez contends that social scientists have a poor record for experimenting with our own means of production and performance (Corsín Jiménez 2014:387). I suggest that noted exceptions to this, although perhaps not deliberately phrased as experiments, are the collaborative production of ethnographic texts with interlocutors and the activist and applied anthropology research that champions communitybased involvement and responsibility towards publics outside the academy (cf. Kemmis and Taggart 2000, Lassiter 2005). Another example 
of anthropological collaborations, in this case consciously labelled as experiments, are "the Labinars" of Paul Rabinow and affiliated students who have been experimenting with venues and practices including collaborative ways of designing, analyzing and disseminating anthropology - and with ways of doing collective conceptual work (cf. Korsby and Stavrianakis 2016, Rabinow 2014b). In his investigation of modes of experimentation in anthropological research, George Marcus notes that the impulse to experiment in ethnographic research has migrated from innovations in theory and writing to the realm of fieldwork practices (Marcus 2014:399). Marcus suggests that we can think of modes of experimentation during fieldwork as prototyping. He lays out two modalities of experimentation differentiated by degree of restraint towards a particular end product such as an authoritative textual genre. Type 1 prototyping, the most common kind, are experiments in what Marcus terms a "disciplined mode" - i.e. they are stable and constrained by genre outcome. In contrast, type 2 prototyping is unstable and openended as this type of experimentation is less pressured by requirements to produce particular kinds of results such as marketable products or implementable solutions (Marcus 2014:400-403). According to Marcus, the proliferation of anthropologists' engagements with external collaborations and new field sites in complex organizational environments makes experimentations increasingly necessary. In consequence, anthropologists' prized "lone wolf" endeavors "must somehow be fit into collective, yet parallel, forms of inquiry already occurring in sites and circuits of fieldwork" (Marcus 2014:400).

\section{Methods on the Spot}

In 2016, I was hired by the Danish start-up Exruptive A/S as a consultant to gather qualitative data about user experiences and behavior during user tests of a new security concept. ${ }^{1}$ The Exruptive airport security concept comprises a next generation X-ray scanner for carry-on luggage and scannable "intelligent trolleys" ${ }^{2}$ and the tests would take place in a custom-built factory test site. In reflection of the company's cashcrunched financial reality, I was hired on an hourly basis for the six nonconsecutive days that the "Flow Tests, Phase 1" (FTP1) were scheduled for. Besides co-writing some sections of a so-called "Test Manual" some months earlier, I had not taken part in the test preparations.

In the 2.5 hour-drive from the company's offices to the Test

\footnotetext{
${ }^{1}$ I had been involved with the company some months previously to help develop a strategy for how, when and why to include qualitative research in their technology design and development process. Together, we had also applied for the industrial postdoc funding that forms the basis for my current position with the company and the Department of Anthropology, University of Copenhagen.

${ }^{2}$ The Exruptive trolleys are referred to as Intelligent Trolleys and Smart Trolleys interchangeably within the company, mirroring buzz word of smart, intelligent design and technology. For sakes of consistency, I refer to them here as intelligent trolleys.
} 
Center, I was in the backseat of one of the two cars transporting staff members and project partners to Jutland for the tests. With me on the backseat was an engineer nicknamed Wonderboy ${ }^{3}$ who was in charge of this phase of user testing. The idea was for us to spend the time in the car "productively." This meant, firstly, that a lot of information was relayed to me about the work the team had carried out in the months since our last contact, including the decisions about the physical set-up in the Test Center. Secondly, information about the first Test Day was conveyed: how many testers are expected, how long is the test, how many staff members will be present, etc. Based on this, we brainstormed about where to place staff and how to divide the testers into groups to start within different intervals. Next, I was then expected - on the spot - to come up with a plan for how to gather qualitative user experience data during the test some hours later. With the generic Test Manual already written, the team had not considered further methodological preparation for the test to be necessary.

Still trying to order and absorb all the information I had just been given, and not least think through its impact on methodological choices, I started deliberating different options out loud. Tentatively, Wonderboy suggested - based on my own examples of methods from the Test Manual, he said - a triangular multi-method and multi-foci approach. This would include follow-the-tester/trolley observation during the test, post-test focus groups about design (in adjacent offices) and post-test but onsite semi-structured interviews about user experience. His suggestion lead to a spirited discussion about the merits of a focused approach versus the possibility of gathering user feedback of many different kinds. However, since the testers had not been briefed about the conduction of focus groups nor longer post-test interviews, I reasoned that the choice of such methods would be in breach of the implicit contract with them about the event they had signed up for. Also, I maintained that to work well both focus groups and semi-structured interviews require planning and preparation, e.g. of interview guide, participant and setting selection. As such they were not, in my opinion, suitable methods for the extent of improvisation that I understood Wonderboy to be suggesting.

Early on, I thus experienced and expressed a limit to my own willingness to undertake experiments - a line I intuitively drew at what I interpreted as inconsiderate and uncritical method application. This indicates, I suggest, the value-addition stemming from preparing and thinking through experiments, e.g. their purpose, extent, and framework, rather than taking to experimenting (purely) as improvisation necessitated by context and resource restraints. Instead of the impromptu focus groups and semi-structured interviews, I favored the idea of doing

\footnotetext{
${ }^{3}$ This nickname was coined by the then CEO in appreciation of the engineer's skills in visual design which helped the team transform rather dull and wordheavy PowerPoint slides into delightful visual presentations, i.e. works of wonder. Other staff members were also nicknamed, e.g. one with a pun on his surname and myself and another colleague holding a $\mathrm{PhD}$ degree were known as "the eggheads."
} 
follow-the-tester/trolley observation during the test to explore what kinds of data such methods could generate. But Wonderboy questioned whether this approach alone could generate enough data about the testers' experience and secure a desired variation in feedback.

Furthermore, I was now informed that the core purpose of the test was in fact not to gather qualitative user feedback but to quantitatively measure flow, i.e. how long it took testers to move through the simulated airport with the Exruptive security concept. And, argued Wonderboy, placing a researcher in between the users might disrupt or change the flow measurements in unforeseen ways. At the same time, Wonderboy said he liked the idea of methodological experiments such as follow-thetester/trolley. However, I implicitly understood that such experimentation, and its related uncertainty in terms of output, was better placed later on in FTP1 or even in later test phases. That is, once the user testing was well underway and a "good amount" of user feedback had been gathered. ${ }^{4}$ And, perhaps, once familiarity, confidence and trust in me as an engaged member of the team was established - following Niklas Luhmann's series of relation building - as with trust follows an increasing willingness to take risks (Luhmann 2000, Rabinow 2014a:171).

I suggest that this conditioned openness towards experiments makes two things apparent. First, it renders visible the temporal rhythms of the technology development process and the state of the start-up company. That is, the need for particular kinds of data to feed into company sales pitches resulted in the favoring of numbers - such as throughput numbers that could be compared to those of existing airport security solutions - over open-ended qualitative explorations of user experience in the beginning of the test phases. My own - and the team's room for experimental maneuvering was thus based on configurations of the company's data needs at any given point in the process - not just in terms of internal technology development processes but also in terms of externally presentable data that could be used in concept pitches to investors for instance. Following Marcus, this constitutes a disciplined mode of experimenting in which the need for a particular end product is restraining the degree and kind of experimental exploration and, in this case, perhaps even lead to the lack of conscious acknowledgement about this user testing process as an experimental mode of inquiry. So, although the process of user testing can in itself be seen as an exploratory endeavor undertaken by the company (i.e. experiments with how to user test new technologies), this perspective was not - at the time - prevalent internally among the team members. They seldom talked about the testing process itself and their own work practices as experimental. Rather, user testing was approached as a set task in the cycle of technology development with the purpose of gathering particular data to

\footnotetext{
${ }^{4}$ The imaginary "good amount" of user feedback was not defined in terms of numbers (X number of tester's statements) but rather loosely talked about as enough qualitative feedback about user experiences and interactions to drive the design further.
} 
further the development process - and not as an exploration of ways of user testing. During FTP1, I often repeated that I found central learnings from the Test Days to be as much about test form as about user feedback content. In other words, that the company was not just user testing but also testing user testing and thus acquiring knowledge about how to best conduct such tests. While this statement was at first received with some skepticism especially with regards to the value of such learnings, I gradually found it reiterated among the team.

\section{The Compromise}

While covering the last stretch of highway towards the Test Center and with the experimental confines made clear, Wonderboy and I reached a decision. We would combine observation ${ }^{5}$ with something that I, for the lack of another term, have called "speed-interviews," i.e. short conversations onsite with selected testers as they finished each round of tests. The speed interviews represented a compromise compared to the semi-structured, life-story and open-ended interview styles that I have favored in previous projects (Ilkjær 2011, 2015, 2016). However, the push towards this unknown ground was a chance to experiment. First, in terms of first approaches to the interviewee - walking up to them or inviting them over to my table without having a prior interview agreement - and conducting the speed interviews on site in the crowded test hall. I have come to think of this as "cold-starting" an interview. Secondly, the speed interviews were experiments with regard to length and the related impact on rapport-building and types of questions. At times, I found myself switching intonation and wording to better reflect the local dialect (I grew up in the area) as a way of testing out relatability. And, I usually started the conversations with open questions - for example a simple "how did it go?" - after which I moved on to more specific topics such as the user interface (UI) ${ }^{6}$ or pursued the phrasings and themes raised by the interviewee. The speed interviews were thus iterative experiments with interview form and structure, including speed evaluations between test rounds of what worked and why - and consequent reorientations.

In terms of data generation, the outcome of the speed interview experiment put my initial fears to shame. Besides generating various feedback about the testers' impressions of the UI, it also provided input on testers' learning curves when faced with unfamiliar devises and situations and insights into testers' way of testing things, i.e. their handson experimentation with the technologies during the tests. However, I

\footnotetext{
${ }^{5}$ The observations would be carried out by various members of staff at selected spots in the Test Center during the tests. Besides the author, no members of staff have training in qualitative methodology.

${ }^{6}$ An interface can be defined as "the site at which the human body interacts with a complex mechanical apparatus." In a "man-machine system," the interface is thus the hyphen between "man" and "machine" (Harwood 2011:9).
} 
found that the speed interviews provided hardly any insights about testers' (total) experience of the Exruptive security concept. This has less to do with the method and more to do with the test set-up which did not really, as it turned out, cater to the testing of user experience. I will return to this point in the discussion of the Test Center as a testing facility. In terms of evaluating the learnings from the speed interview experiment, I follow Rheinberger's caution that we should consider experiments from a connected and processual perspective rather than judge them individually (Rheinberger 2009). And so, in order to zoom out from the micro-processes of my own experiment, I will now situate it within what I see as a larger and interconnected experiment towards the future airport.

\section{The Exruptive Technologies}

In 2013, Exruptive began developing a new modular range of technologies to improve security procedures and passenger experience in airports. The company's self-proclaimed "disruptive innovation"7 approach prescribes what they present as a radical rethinking of the currently-known security procedure and a conceptual re-imagining of the security area. Enabled by patented next generation scanning technology, ${ }^{8}$ the Exruptive security concept replaces the existing tray system with scannable intelligent trolleys that guide the passengers through the security procedure via a customized UI on a mounted tablet. The enhanced scanning technology eliminates the need for passengers to unpack liquids and electronic equipment, instead they can load their carry-on items directly onto the intelligent trolley and have the trolley proceed through the scanner. The concept is designed to significantly increase the throughput of passengers per security line, to minimize the need for manual searches of passengers' belongings, and to secure a high level of information to the passenger at all times. The Exruptive security concept aims to link the passenger's entire journey through the airport from security to gate via the intelligent trolley. It is this approach that constitutes what I see as the company's experiment: the experiment in market disruption.

If we take Exruptive's approach to be experimental, what does this reveal about the existing airport attitudes and ways of operating? As the physical structures that represent starting points, stop-overs or final destinations of a journey, airports are unsurpassable factors when people are travelling by air. However, in a little over 100 years, airports have transformed from being seen as places of excitement to increasingly

\footnotetext{
${ }^{7}$ Disruptive innovation is defined as innovation that disrupts an existing market or displace an earlier technology. The phrase was coined in the 1990's by Clayton Christensen but the concept of innovation through "creative destruction" was originally popularized through Joseph Schumpeter's theories from the 1940's (Haines 2016:177).
${ }^{8}$ Exruptive has developed this patented multi-energy X-ray scanning technology in collaboration with researchers at the Physics Department of the Danish Technical University (DTU).


maligned aspects of modern culture (Budd 2012:151). One of the issues plaguing airports, according to industry reports, is the predominant mode of silo organization, i.e. the running of an airport as a set of co-habiting but separate entities each responsible only for distinctly marked areas and operations (e.g. airport, airline, ground handling, police and immigration, concessions). ${ }^{9}$ The silo mode results in experiences of sequential but detached zones of slightly different approaches, for example, in ways of communicating with and servicing the passengers. With reference to the harmfulness of detached entities on the overall passenger experience, airport integration is a focus theme at aviation conferences. In the experiment towards seamless airport experiences, many stakeholders look towards new technologies that, for instance, enable pre-processing and passenger self-service such as biometricsbased pre-clearance of security through integrated digital identity management. The Exruptive technologies also address this seamless passenger-centric airport experiment.

\section{Grounding the Airport Experience}

When looking beyond the current organizational and operational silos, what kind of spaces are airports? Since the publication of Marc Augé's seminal anthropological work, most research on airports have readily accepted his labelling of them as non-places meaning that they are "not defined as relational, or historical, or concerned with identity" (Augé 1995:77-78). In other words, airports as non-places are made impersonal by their intended transitional purpose. ${ }^{10}$ Consequently, airports are often depicted as entirely fluid, placeless sites of global connectivity - "spaces of flows" (Castells 1996) - that are only there to be passed through; the "transition points between earth and sky" (Budd 2012:151). Yet, others have argued that to focus solely on the transitory aspect of airports is too one-sided. Not just because airports are increasingly securitized spaces of policing that allow for the passing of only certain kinds of subjects (cf. Adey 2003, Maguire 2012, Salter 2007). But also because the flow approach disregards the importance of locality and leaves out perspectives of continuity and everydayness from our understandings of airports (Moreland 2013, Sharma 2009). An alternative approach is to examine airports from the point of view of the employees who spend time there daily instead of just taking the occasional traveler's perspective. Yet, with the exception of Brenda Chalfin's work on custom's officials in Ghana's international airport (Chalfin 2008, 2010) employee-focused airport studies are scarce.

I suggest that another way to move beyond the one-sided transitory view is to look at airport self-understandings as presented in

\footnotetext{
${ }^{9}$ See for example https://www.iata.org/pressroom/facts_figures/Documents/vision-2050.pdf

${ }^{10}$ Besides airports, Augé also mentioned railway stations and malls as examples of non-places.
} 
their marketing strategies. Doing so, I find that airports are increasingly focused on promoting passenger experience and looking to situate themselves as special places. That is, airports are seeking to highlight the particularity of their locality in order to market and sell that very airport space as a special place. I propose that we think of this as experiments with grounding the airport experience. In Cincinnati/Northern Kentucky International Airport (CVG) they have, for example, teamed up with the local art scene to create micro-entertainment zones to showcase artifacts from the Cincinnati Museum Center and to host performances by the Cincinnati Ballet. Further, the airport has miniature horses trotting around the terminals twice a month. While this is in part paying tribute to the local area as farming country it is also an experiment in using animals to ease travel anxiety. ${ }^{11}$ In Amsterdam Schiphol Airport (AMS), they exhibit original 17th-century art pieces from the city's world famous Rijksmuseum $^{12}$ and in Austin-Bergstrom International Airport (AUS) they have fitted the baggage reclaim area with giant guitars intended to welcome passengers to "the live music capital of the world." ${ }^{13}$ These are some examples of how airports seek to ground the experience and move away from previous images of sterile environments and identifications as non-places of passage (and/or surveillance). Instead, airports now focus on locality and the facilitation of good experiences, identifying this as key to passenger satisfaction and increased passenger expenditure (Høst 2015, Lloyd 2003). Yet, no matter the amount of work done on locality branding, a key factor currently known to stand in the way of good airport experiences are the security procedures. The security area - and getting through the security process - constitutes major sources of stress, irritation and anxiety for passengers (Gregg and Peel 2015, Martin 2010, SITA 2015). It is precisely this current weak spot in the passenger experience of airports that the Exruptive technologies and security concept target for improvement.

\section{Technology Testing as Market Preparation}

Before the Exruptive technologies can be introduced to the market, they must prove their efficiency, reliability and experience-improvement potential through various tests. For particular kinds of new technologies, e.g. security-related equipment, there are standardized procedures for laboratory testing of their capabilities. ${ }^{14}$ For other kinds of new

\footnotetext{
${ }^{11}$ See for example https://www.cntraveler.com/story/this-airport-has-minihorses-to-help-you-relax

${ }^{12}$ See https://www.rijksmuseum.nl/en/schiphol

${ }^{13}$ See https://austintexas.gov/department/permanent-art-airport for more on the art projects in Austin Airport.

${ }^{14}$ New security equipment such as luggage scanners must undergo rigorous laboratory testing performed by particular appointed bodies like the ECAC in Europe, TSA in the US and CATSA in Canada. The purpose of the laboratory tests is to measure the equipment's capabilities against some set performance standards. In Europe, the testing procedure result in a classification of the
} 
technology, such as tablets and trolleys, there are no such official security-related testing procedures. ${ }^{15}$ Testing of the Exruptive tablet and trolley is thus not mandatory for reasons of them being security-related equipment. Yet, the company still considers pre-market testing to be central, in part reflecting their ambition to involve users in all stages of the development process, but also as a way to strengthen the company's sales pitch and to provide data to enable comparison of the Exruptive security concept, for example in terms of throughput and commercial revenue, to existing products on the market. To enable user testing, Exruptive had a Test Center built. This was to serve as a custom-made site for various technical and user tests but also, I suggest, for other kinds of testing. This includes experiments with how to build and continuously develop a physical environment that functions as an appropriate and enabling scene for precisely the kinds of (user) tests needed at different points in the development process. Besides the experiments with the physical scenery, the Test Center is also a place for the experimental staging of space. By this I mean spatial trials with creating a kind of simulated yet believable airport setting, i.e. an in-between zone that strikes the right balance between the known and the unknown, the recognizable and the new, reflecting elements of current airport scenarios while allowing room for the imagination of alternative future scenarios. Let us now explore this multi-experimental Test Center setting further.

\section{The Test Center}

The Test Center is located in rural surroundings in south eastern Jutland next to the small regional Vojens Airport ${ }^{16}$ and Flyvestation Skrydstrup where the Royal Danish Airforce have their F-16 fighter division stationed. The heart of the Test Center facility is a newly-built $420 \mathrm{~m} 2$ hangar, "the test hall" or simply "the hall" among staff. The high-ceilinged interior has chipboard walls and white-painted concrete floors. The hall is dominated by a large white structure with a blue Exruptive logo on the side: a mock-up scanner that somewhat resembles the design drawings of the scanner that Exruptive is developing. At either end of the front of this mock-up scanner, three rectangle-shaped cut-outs represent the idea of "inlets" - where trolleys are to enter the scanner - and "outlets" - where trolleys exit the scanner. When I first visited, dark grey towels were partly

technology into a standard or marks it as rejected. Knowing a scanner's standard based on the ECAC test, an ECAC member state can then certify the scanner to enter their market, or they may choose to demand additional tests (the UK and France do this, for example).

${ }^{15}$ Yet, a general safety approval is needed for all products, e.g. like the CE marking. However, as a colleague involved in preparing for the laboratory testing of the Exruptive scanner expressed it, the CE approval of the Exruptive trolley and tablet is regarded as a formality that is easily overcome in comparison with the strict and extensive certification procedure for security equipment.

${ }^{16}$ The number of passengers through Vojens Airport on civilian aircrafts stand at 1200 passengers in 2015, 1200 passengers in 2016 and 116 passengers in 2017. 
covering the holes of the inlets and outlets, obstructing the conveyer belts that run through the interior of the mock-up scanner from view. The towels have since been replaced by plastic flaps, thus providing one example of the continuous experimentation with building a test set-up that reflects the technologies (or mock-ups/prototypes hereof) to the desired extent while simulating an airport-like space to varying degrees of material realism.

Part of the test hall is divided into lines by the use of Tensabarriers, forming a path towards the inlets and further on towards a mock-up metal detector: a white, rectangular box standing by itself on the floor in the middle of the hall. ${ }^{17}$ When the Test Center is in use, the roller door at one end of the hangar is kept open, letting light and air in and providing passage into a covered corridor made from two red-and-white tents with plastic window panels. ${ }^{18}$ The tents are pitched on the cobbled path at the rear of the hall and form a large L-shape which connects to another hangar known as "the old hall." ${ }^{\text {19 }}$ Inside the old hall, another three $6 \times 12$ meter tents form a separate space. One side of the tents are covered with large blue-toned generic pictures of airport scenery (highceilinged buildings with lots of signage). The tented space in the old hall is the starting point for the tests in the FTP $1 .{ }^{20}$ Rows of trolleys occupy the concrete floor here, 90 in total. The trolleys, rented from Copenhagen Airport since the (prototypes of) the intelligent trolleys were not yet manufactured, are central props for the flow tests. Equally central are the approximately 90 testers who have signed up to be part of the two-hour test session. ${ }^{21}$

It is often the case that companies farm out the process of recruiting potential users to take part in product testing, e.g. by hiring a market research company to supply users from sets of pre-given demographic preferences. Instead of this commercialized approach, Exruptive experimented with what can perhaps be described as a

\footnotetext{
${ }^{17}$ After FTP1, a real working metal detector was lent to the Test Center by the airport next door, meaning that this part of the set-up will strike a more materially realistic tone for future tests.

${ }^{18}$ Such tents are commonly referred to by Danes as "party-tents" as they are often put up for garden parties.

${ }^{19}$ This name is a likely reference to the fact that this structure pre-dates the company's use of the site.

${ }^{20}$ The starting point for the test was subsequently revised and changed as a result of the analysis of feedback given during the six days in FTP1.

${ }^{21}$ In total, 631 testers took part in the six Test Days of FTP1. The testers were between 12 and 79 years old. A number of younger children also participated with family members without them being registered officially as testers. The testers came from, for example, the local football, riding, and bicycling clubs, the scouts, the model train association and the voluntary fire brigade. Some testers participated alone, some with spouses, children, grandparents and friends. Some testers were visually or hearing impaired, some brought baby strollers, walkers or walking canes.
} 
community-based model of recruitment. This model centers around the Head of the Test Center building long-term relations with local sports and hobby-based associations and then recruiting testers through these local associations. Instead of paying the testers personally, the model is constructed so that in return for each tester's participation Exruptive donates a fixed amount to their association and a fixed amount to a national charity. The testers receive no training or instruction, actually they receive very little information about the test beforehand. This strategy of withholding information is deliberate in the attempt to create a set-up in which it is possible to test the immediate reactions and behavior of people who have no prior knowledge or experience with the Exruptive technologies and security concept.

Once the testers arrive at the Test Center, they are registered. The registration takes place in the courtyard - initially open air but during latter tests in a tent - and comprises the matching of each tester with a number and a personal form including information about their (selfascribed) technology proficiency, travel habits, educational background, etc. $^{22}$ Once all testers have been registered, there is a collective welcome speech and then the testers line up along the hangar wall, waiting to be let in. The staff member at the entry lets them in in specific intervals and sizes of groups depending on which flow conditions are being tested in each round. ${ }^{23}$ Once the testers are inside the tents in the old hall, they are meant to take a trolley (from any of the rows), to load it with their carryon luggage and bring it to the scanner for security check, then go through the personal security check and finally pick up their trolley from the scanner outlet. The testers are guided through this process by instructions displayed on the UI and on posters hung in various places throughout the hall and by personal staff assistance in selected spots.

\footnotetext{
${ }^{22}$ The form was sent out as an attached document to all testers beforehand. Whereas some testers filled it out and returned it digitally, others brought printouts of their filled form, yet again others had not filled out anything beforehand. Depending on the testers' pre-test form-filling (in)action, they had to be met with different procedures when arriving at the registration on the Test Day. The staff spotted inefficiencies in the registration procedure already during Test Day 1 and different attempts to streamline it were consequently enacted. By Test Day 5 and 6 , the onsite registration was separated by categories so that there were different tables of address for testers who had filled out forms beforehand and for those who had not. After all tests in FTP1 were concluded, the information from the forms was manually entered into a database. To eliminate this work and to improve the speed and flow of the onsite registration procedure, the team decided to make digital prefilling of the information form mandatory for all testers starting from "Flow Test, Phase 2" and onwards.

${ }^{23}$ This was discussed among the team based on the results from the previous test day and finally decided at the pre-test staff meeting.
} 


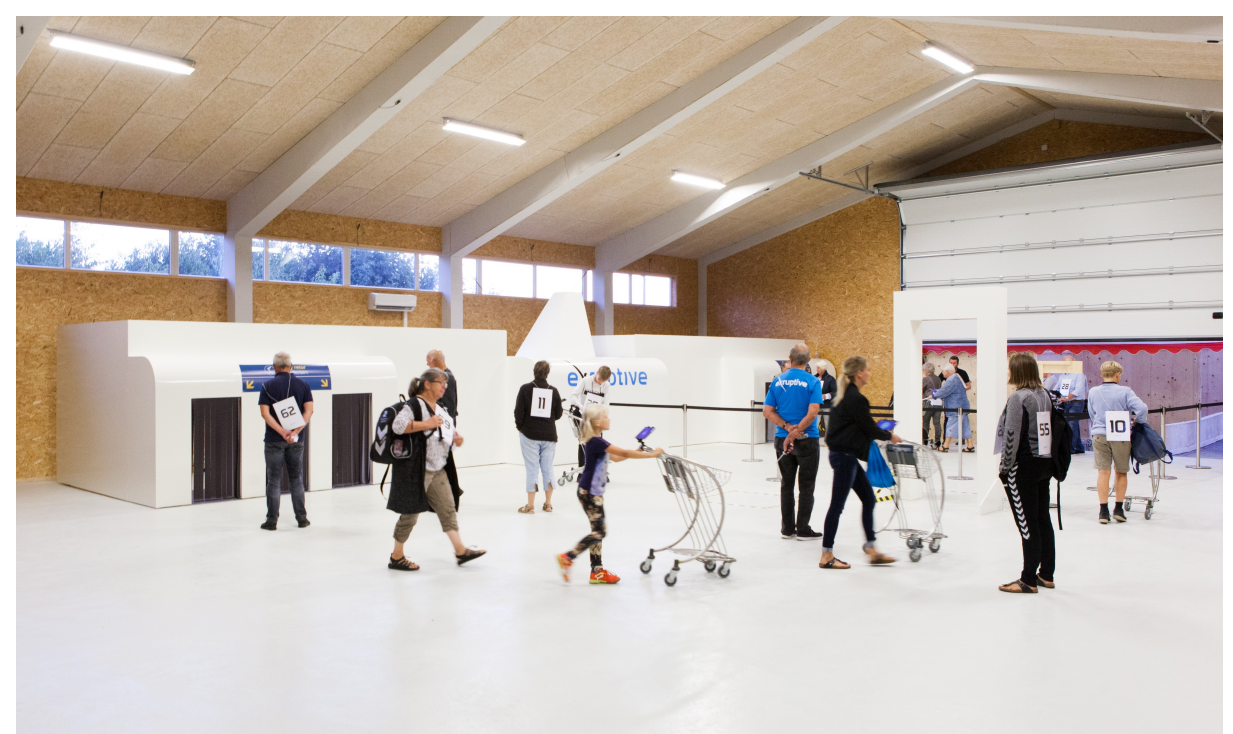

Figure 1. User Testing with Mockups and Prototypes in the Exruptive Test Center. Photo credit: Lasse Baltzer. Photo reprinted here with permission.

\section{Tests Within Tests}

The focus of the first three Test Days (in FTP1) was primarily on establishing a baseline in terms of throughput per minute and, by extension, hour. Test Days 4 to 6 incorporated trials of various communicative elements. All six days, though, can be viewed as iterations of experimenting. During the six days, the team tried out various constellations of mechanical and human flow conditions. For example, there were experiments with different numbers of testers starting within the same minute, with the speed of the scanner conveyer belt, with the trolley entry and exit intervals from the scanner, and with the ratio of full body scans at the metal detector. These experiments were undertaken with a view to explore potential bottlenecks - sites, situations and stressors - and to start building an understanding of various factors' quantitative and qualitative impact on the Exruptive security concept, i.e. on the throughput as well as on the testers' experience. In addition to the various speed experiments, the built test set-up itself went through stages of experimentation in the sense that things were changed from Test Day to Test Day. The point of these micro-experiments, or tests within the test, was to assemble knowledge about how the physical setting might impact the flow and the testers' experience, i.e. what elements cause larger impact (positive or negative) and what stages in the security process are the most crucial crossroads in terms of enabling, for example, feelings of clarity/confusion, security/insecurity. Sometimes these experiments meant that parts of the physical test set-up were moved around (such as partition walls simulating corridors), at other times it meant that items were removed or that new elements were added. Before Test Day 3, for example, a rudimentary sensor attached to a light panel was mounted above the inlets. Whenever a trolley was inserted into a particular inlet, the light would change from green to red, signaling the unavailability of that inlet. The sensor worked on a set time interval (rather than working from data about the actual amount of trolleys on the scanner conveyer belt), and the idea of adding the sensor and the light panel was to include 
the element of occasional inlet unavailability to the test. This was done in part to make the test set-up more realistically reflect the amount of trolleys that the scanner can handle per minute but also to test the testers' responses to red lights, including their resultant actions.

Besides experimenting with the physical set-up and with speed conditions, there were also ongoing alterations to staff based on who was available to join the test on any particular day ${ }^{24}$ but also reflecting a gradual process of (realizing the need for) defining the staff roles, for example, in terms of behavior at different posts in the simulated test airport setting. I suggest that we think about the staff changes as experiments with human-to-human factors in the Test Center setting, albeit they were only partially planned and ideated as such. Variant performances of roles such as the one as "security officer" by the metal detector were naturally exposed as different staff members stood at different positions on different Test Days. The variation in performance of roles is what I suggest served as an unintended, yet very relevant, experiment with the impact of different staff attitudes and service approaches. In addition, more deliberate experiments with role playing were also incorporated in the tests, i.e. on different Test Days the staff member positioned at the inlets was told to enact various "modes of strictness" with testers who had not followed the security check preparation guidelines. At other times, though, staff members would take matters of role playing into their own hands, such as when the retired policeman who played the role of security officer on Test Days 4 to 6 brought a screwdriver to the tests. The screwdriver, he explained to some of us in the minutes just before the start of the first round, was meant to simulate the hand-held metal detector that is sometimes used in airports when passengers are selected for additional checks. Throughout the test rounds that day I saw him simulating scanning movements up and down the bodies of testers, causing laughter among some and facial expressions of discomfort from others. After FTP1 ended, a collaborate evaluation of the learnings from the different experiments with staff behavior, intended and unintended, resulted in the writing of a manual for staff roles. In the description of the security officer role the screwdriver was decidedly left out.

Some of the decisions about staff behavior were taken not so much as means of testing the testers' responses to different roles but rather as a way to ensure that an image of professionalism and seriousness surrounded the tests. For example, the voluntary staff in the scanner (four local children and two parents) were asked to remain silent during the test rounds to avoid the impression of a laughing and talking

\footnotetext{
${ }^{24}$ The company itself has too few employees to fill the necessary posts during the test. Therefore, the test team - beyond the 5-7 company employees available to take a day out to go to Vojens - usually comprised a mix of affiliated students (from DTU and Copenhagen Business School), employees from a partner and a sister company and local volunteers (as the scanner crew). During FTP1, I was counted as an external participant to the team, identified in test summary documents as being from the University of Copenhagen.
} 
scanner. This step was taken after Test Day 2 based on some of my observations which suggested that the human sounds coming from the scanner confused the testers and further that the "laughing scanner" potentially influenced testers' experience of the concept, for example prompting considerations about the safety of their belongings. I found this to be manifest in statements such as the following from tester 32 , Test Day 2, round 1, who said: "I thought about the fact that I cannot see what they are doing to my luggage. You cannot see whether they are tampering with something in there [om de piller i noget]." Whereas the real Exruptive scanner will be fully automated, the audible presence of humans inside the mock-up scanner in the Test Center created a test situation that was completely opposite to the final security concept. This radical difference, I suggest, lead to a gathering of experience feedback that was, at best, irrelevant in the sense that the experiences referenced a situation (possible human interference with passengers' belongings) that is completely unlikely in the final version of the concept. And, perhaps worse, experiences of a laughing scanner at the end of the test may have overshadowed other impressions from earlier on in the test, thus potentially skewing the testers' total experience - and feedback accounts of it - and by extension, the team's understanding of user experiences.

\section{Prototypes and Development Cycles}

The user tests in the Test Center followed in the footsteps of a variety of earlier stage (user) tests. Once the idea for a new way of airport security had been hatched, studies were conducted in Copenhagen Airport by, among others, a current company employee to evaluate the feasibility of such a new concept as well as to start mapping potential stakeholders, project infrastructure and user needs. This kind of study to gather initial impressions from stakeholders and users towards a concept idea is sometimes referred to as "pretotyping" (Savoia 2011). Based on the learnings from the Copenhagen Airport study, the conceptual development of the Exruptive security system progressed into the design of a number of prototypes. The idea of a prototype is to represent a state of evolving design and to explore options going forward (Houde and Hill 1997). A prototype can thus be advanced in development, but it must stay open for revision and rethinking (Marcus 2014:399). This openness means that prototypes act as form and content negotiators - or "sociomaterial mediators" in Alex Wilkie's terms - in the meeting between designers and users in product development processes (Wilkie 2014:477). As such, prototyping can in itself be understood as a creative experimentation process in which the developer(s) engage with various others (users, stakeholders, non-experts) and invite them to participate by sharing their ideas, suggestions and so forth (Corsín Jiménez and Estalella 2010, Marcus 2014). 
Pretotyping the Exruptive Security Concept

Airport field study to gather stakeholder and user input on the concept feasibility
Computer simulations of flow and throughput

\section{Mock-up User Interface Tests}

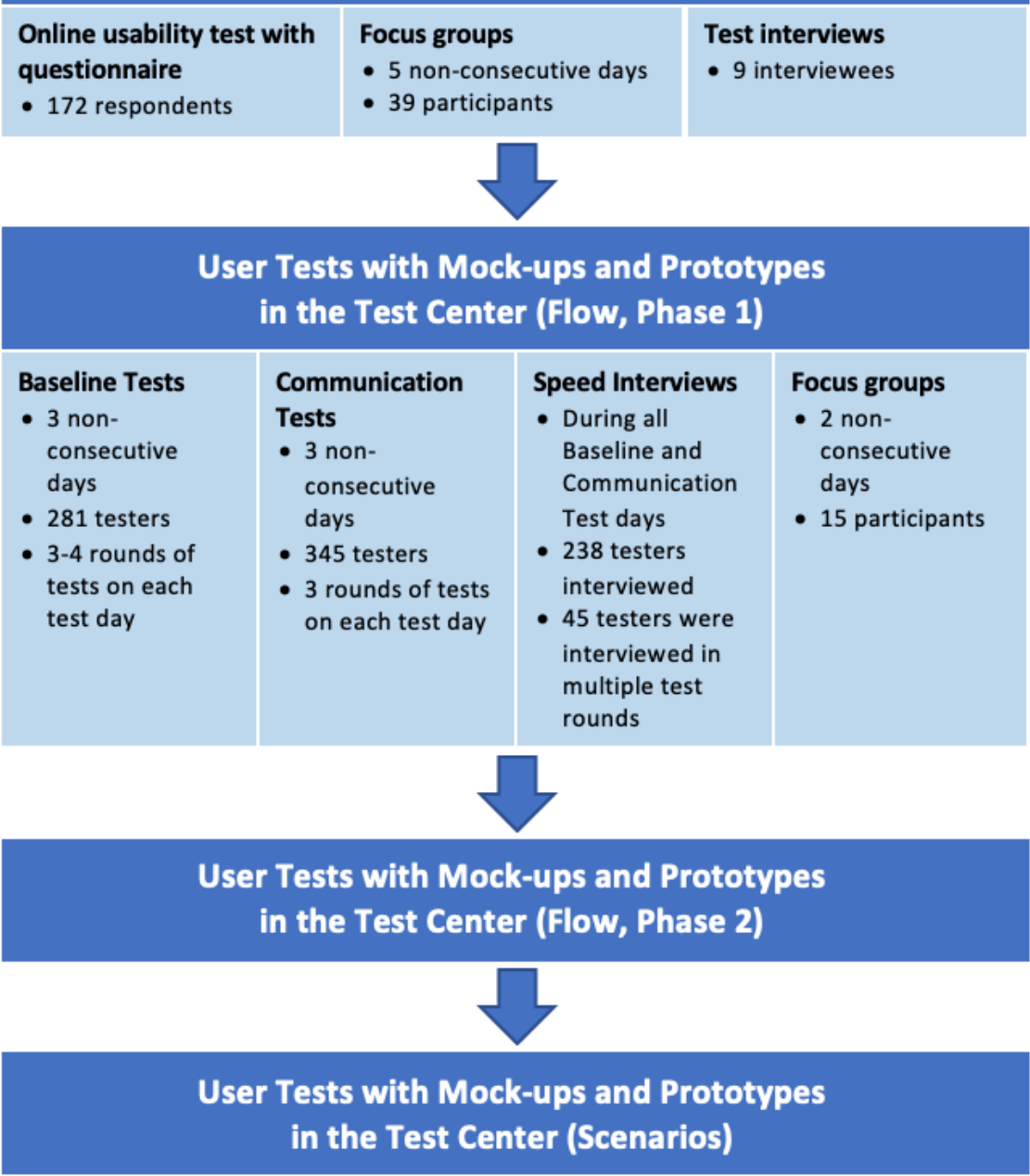

Figure 2. Outline of the phases and various methods employed to user test the Exruptive security concept, product mock-ups and prototypes.

Before initiating the FTP1 in the Test Center, a number of preliminary user tests with prototypes were carried out in various company office premises. Lead by Wonderboy, these user tests included five focus groups with a total of 39 volunteer participants and consecutive "test interviews" 25 with nine of them. The goal was to gather early-stage user impressions and feedback about the look, structure and logic of the

\footnotetext{
${ }^{25}$ When I asked about the meaning of the term "test interview," Wonderboy explained that they wanted to assess whether the testers would give more, or different, feedback in individual interviews compared to during a focus group session. The test element of the test interviews was thus conceptualized as being primarily about testing methods and the related output (rather than prototype product testing).
} 
design and layout of the non-programmed prototype of the tablet UI, referred to by the team as the "mock-up UI." The term mock-up UI resembles what others have called "low-fidelity prototypes" (Rudd, Stern, and Isensee 1996:78). Such early prototypes focus broadly on the idea and the conceptual features of a product or system. In this case, the mockup UI featured an initial schematic with a map, top bars and menus with none of the features being programmed yet, meaning that nothing happened when a user touched the interface. In parallel with the qualitative methods, online usability tests with follow-up questionnaires were conducted with 172 respondents. The purpose of this method was to gather quantitative data on the use of the user interface, e.g. about clusters of clicks, to complement the qualitative feedback from the focus groups and interviews.

In contrast to these preliminary tests, the Test Center incorporates material elements of airport settings. This means that the user tests over time moved closer to testing in a context that resembles, or simulates resemblance to, the end-user setting. Although the first Test Center tests were referred to by the team as "Flow Tests," I suggest that they were in fact experiments in prototype testing of the entire Exruptive security concept. In other words, the material airport simulation component meant that the Test Center tests were not just user testing of product prototypes but also of the concept prototype, i.e. the Exruptive security concept. The concept prototype was a complex assemblage made up of different elements at different stages of development. These various elements were staged in an environment that at the same time incorporated recognizable elements of standardized airport equipment (the Tensa-barriers, the mock-up metal detector) while also trying out new spatial arrangements (e.g. in terms of queue management). As has been noted by others, it can be difficult or impossible to create prototypes of a whole design in the formative stages of a product (Houde and Hill 1997:367). In this light, it is perhaps not surprising that the analysis after FTP1 suggested that the experiment in simultaneous testing had failed, particularly affecting the attempt at prototype concept testing. That is, the Test Center setup was at that point found to be an unsuitable setting for generating qualitative data about the concept as a whole (e.g. user experience of the Exruptive security concept). Whereas interesting and important feedback about the particular product prototypes (the UI) had been generated, the feedback from the testers about the concept prototype was found to be lacking or irrelevant. This was heavily influenced by the fact that spatial and experience elements of the concept prototype (e.g. the architecture, sounds and stress of airports) were either absent from the test setup or too different from the actual end-user situation. That is, the concept prototype was not built or staged in a way that could produce feedback from users that addressed the open design questions at that phase of development. As a result, the team decided to improve the concept prototype, i.e. work to make the Test Center setup more airportlike, before conducting further concept prototype tests and to dedicate a phase of future user tests to the testing of particular experience and communication scenarios. 


\section{Conclusions}

The increasing involvement of users in product development processes reflects a shift in relations between designers and end-users. In the Exruptive case, I suggest that we consider this as more than a shift in design processes but also as an experiment with unofficial certification of disruptive innovation products. That is, the user tests are a necessary step in the company's work to create recognition and faith in a radically new security concept and its related technologies. "Seed-stage and early-stage startups are trying to create a product and create a business simultaneously. They are focused on doing something innovative, but also on building legitimacy and showing that they are scalable," explains Julia Haines based on her fieldwork among startups and startup accelerators (Haines 2016:179). Following Haines, I argue that Exruptive needed empirical findings to back up the bold ideas of their disruptive innovation concept and to demonstrate the workings of their new technologies in practice. That is, the company needed - and needs - user tests to prove their concept as well as to generate input for further development and finetuning of its elements. Therefore, the user testing in the Test Center is both an intrinsic part of the technology development process and of the company's legitimacy building as a newcomer within an airport and security industry that is otherwise dominated by large and wellestablished suppliers such as Smiths Detection, L3, and Analogic. The prototype and concept testing thus serve a dual purpose - what we could call internal and external motivations to carry out user tests. The internal - designerly - motivation is to gather reactions and input from potential users about their interactions with and impressions of the prototypes (concept and technologies). This user feedback data is then incorporated, to various extents, by the design team to refine or change aspects of the products in what follows a well-trodden pattern of incorporating user tests in product development processes (cf. Houde and Hill 1997). The external - organizational and business - motivation to test are to use the results, and the general (checkbox) narrative of being a company that carries out user tests, as a way of building twin legitimacy for a radically new concept and a new company at the same time. ${ }^{26}$

In this sense, Exruptive incorporates the tests in its external image-building efforts to communicate thoroughness and capability to investors, potential clients as well as competitors in the industry. I thus argue that we should understand the user tests - both the actual testing process and the company narrative of being a business that undertakes user tests - as a reflection of the two-fold startup company process that needs to be oriented towards product and business building at the same time. The user tests in the Test Center are thus geared towards generating instantly sellable business headliners, e.g. of throughput per hour, as much as it is focused on gathering various qualitative and quantitative

\footnotetext{
${ }^{26}$ For another example of what we could call the checkbox or ritual application of particular work ways or methods, see Peter Dahler-Larsen's analysis of the use of evaluations as a tool for signaling accountability (Dahler-Larsen 1998).
} 
data input for the design and development process. Furthermore, the ability to show scalability in the form of test results of throughput was essential for the company's competition for further funding, i.e. getting the cash inflow to pay for the next phase of development. As such, the user tests were a method for validating the disruptive idea, and hereby evaluating whether the product concept could scale before actually developing it fully. In the Exruptive case, I also suggest that the user tests act as ritual performances to mark specific points of learning, transformation and transition in the design and product development process. Finally, the user tests were experiments in informal certification of a radically new security concept and a legitimizing tool for a new technology - the intelligent trolley - for which there exists no official certification procedure.

The kind of improvised and experimental approach which has been presented is, I argue, born out of the resource restrained yet agile and ever-changing start-up company and product development context and needs. The experimental confines and motivations are influenced by market, social, and economic conditions largely beyond company and employee control, as well as by complex shareholder interests and shifting airport industry trends. In the Exruptive case, the experimental and improvised approach occurred as much as a reflection and result of limited economic and employee resources as an intentional and directed company innovation strategy. In between choice and necessity, the experimental way is integral when developing technologies, security concepts and airport experiences for the future.

\section{References}

Adey, Peter. 2003. "Secured and Sorted Mobilities: Examples from the Airport." Surveillance \& Society 1 (4):500-519.

https://ojs.library.queensu.ca/index.php/surveillance-andsociety/article/view/3333.

Augé, Marc. 1995. Non-places. Introduction to an Anthropology of Supermodernity. London, New York: Verso.

Budd, Lucy C. S. 2012. "Airports: from flying fields to twenty-first century aerocities." In International Handbook of Globalization and World Cities, edited by Ben Derudder, Michael Hoyler, Peter J. Taylor and Frank Witlox, 151-161. Cheltenham, UK and Northampton, MA, USA: Edward Elgar.

Castells, Manuel. 1996. The Rise of the Network Society. Volume 1: The Information Age: Economy, Society and Culture. Oxford: Blackwell.

Chalfin, Brenda. 2008. "Sovereigns and citizens in close encounter: Airport anthropology and customs regimes in neoliberal Ghana." American Ethnologist 35 (4):519-538. 
http://www.jstor.org.ep.fjernadgang.kb.dk/stable/27667510.

Chalfin, Brenda. 2010. Neoliberal frontiers. An ethnography of sovereignty in West Africa. Chicago: University of Chicago Press. https://doi.org/10.7208/chicago/9780226100623.001.0001

Corsín Jiménez, Alberto. 2014. "Introduction. The prototype: more than many and less than one." Journal of Cultural Economy 7 (4):381-398. https://doi-org.ep.fjernadgang.kb.dk/10.1080/17530350.2013.858059.

Corsín Jiménez, Alberto, and Adolfo Estalella. 2010. "The prototype: a sociology in abeyance." Limn (Issue Number Zero: Prototyping Prototyping. http://limn.it/the-prototype-a-sociology-in-abeyance/).

Dahler-Larsen, Peter. 1998. Den rituelle reflektion, om evaluering i organisationer. Odense: Odense Universitetsforlag.

Gregg, Melissa, and Stacey Peel. 2015. "Surviving Security: Humanizing the Passenger Screening Checkpoint." The Future of Air Travel Initiative, http://omediaweb.wixsite.com/foat/whitepapers.

Haines, Julia Katherine. 2016. "Meaningful Innovation: Ethnographic Potential in the Startup and Venture Capital Sphere." Ethnographic Praxis in Industry Conference Proceedings:175-200.

https://www.epicpeople.org/meaningful-innovation/.

Harwood, John. 2011. The Interface: IBM and the Transformation of Corporate Design, 1945-1976. Minneapolis: University of Minnesota Press.

https://doi.org/10.5749/minnesota/9780816670390.001.0001

Houde, Stephanie, and Charles Hill. 1997. "What do Prototypes Prototype?" In Handbook of Human-Computer Interaction, edited by Martin Helander, Thomas Landauer and Prasad Prabhu, 367-381. Amsterdam: Elsevier Science. https://doi.org/10.1016/B978-044481862-1.50082-0

Høst, Vibe. 2015. "Lufthavnens transitområde i et oplevelsesøkonomisk perspektiv." Speciale i Kommunikation, Roskilde Universitet.

Kemmis, Stephen, and Robin MC Taggart. 2000. "Paricipatory Action Research." In Handbook of Qualitative Research, 2nd Edition, edited by Norman K. Denzin and Yvonna S. Lincoln, 567-605. Thousand Oaks: Sage Publications.

Korsby, Trine Mygind, and Anthony Stavrianakis. 2016. "Moments in Collaboration: Experiments in Concept Work." Ethnos. Journal of Anthropology Published online 16 Mar 2016:1-19. https://doi.org/10.1080/00141844.2015.1137606

Lassiter, Luke Eric. 2005. "Collaborative Ethnography and Public Anthropology." Current Anthropology 46 (1):83-106. http://www.jstor.org/stable/10.1086/425658 
Leach, James. 2014. "Choreographic Objects." Journal of Cultural Economy 7 (4):458-475. https://doi.org/10.1080/17530350.2013.858058

Lloyd, Justine. 2003. "Airport Technology, Travel, and Consumption." Space and Culture 6 (2):93-109. https://doi.org/10.1177/1206331203251254

Luhmann, Niklas. 2000. "Familiarity, Confidence, Trust: Problems and Alternatives." In Trust: Making and Breaking Cooperative Relations, electronic edition, edited by Diego Gambetta, 94-107. Department of Sociology, University of Oxford: http://www.sociology.ox.ac.uk/papers/luhmann94-107.pdf

Maguire, Mark. 2012. "Biopower, racialization and new security technology." Social Identities. Journal for the Study of Race, Nation and Culture 18 (5):593-607. https://doi.org/10.1080/13504630.2012.692896

Marcus, George. 2014. "Prototyping and Contemporary Anthropological Experiments With Ethnographic Method." Journal of Cultural Economy 7 (4):399-410.

https://doi.org/10.1080/17530350.2013.858061

Marres, Noortje. 2012. "The experiment in living." In Inventive Methods: The Happening of the Social, edited by C. Lury and N. Wakeford, 76-95. London: Routledge.

Martin, Lauren L. 2010. "Bombs, bodies, and biopolitics: securitizing the subject at the airport security checkpoint." Social \& Cultural Geography 11 (17-34). https://doi.org/10.1080/14649360903414585

Moreland, Jeanette Rose. 2013. "The anthropology of airports: Security and the apparatuses of state borders." MA thesis in Anthropology, Binghamton University, State University of New York.

Rabinow, Paul. 2014a. "An Experiment in Discordancy: Reflections on Familiarity, Trust, and Confidence in Synthetic Biology." In The Accompaniment: Assembling the Contemporary, edited by Paul Rabinow, 154-176. Chicago: University of Chicago Press.

Rabinow, Paul. 2014b. "Venues: The Labinar and the Anthropology of the Contemporary Research Collaboratory." In The Accompaniment: Assembling the Contemporary, edited by Paul Rabinow, 127-153. Chicago: University of Chicago Press.

Rheinberger, Hans-Jörg. 2009. "Experimental Reorientations." In Going Amiss in Experimental Research, edited by Giora Hon, Jutta Schickore and Friedrich Steinle, 75-89. New York: Springer. https://doi.org/10.1007/978-1-4020-8893-36

Rudd, Jim, Ken Stern, and Scott Isensee. 1996. "Low vs. High-Fidelity 
Prototyping Debate." Interactions 3 (1):76-85.

https://doi.org/10.1145/223500.223514

Salter, Mark B. 2007. "Governmentalities of an Airport: Heterotopia and Confession." International Political Sociology 1 (1):49-66.

https://doi.org/10.1111/j.1749-5687.2007.00004.x

Savoia, Alberto. 2011. Pretotype It. Make sure you are building the right it before you build it right. Second Pretotype Edition.

http://www.pretotyping.org/uploads/1/4/0/9/14099067/pretotype it 2nd pretotype edition-2.pdf.

Sedgwick, Mitchell W. 2017. "Complicit Positioning: Anthropological Knowledge and Problems of 'Studying Up' for Ethnographer-Employees of Corporations." Journal of Business Anthropology 6 (1):58-88.

https://doi.org/10.22439/iba.v6i1.5317

Sharma, Sarah. 2009. "Baring Life and Lifestyle in the Non-place." Cultural Studies 23 (1):129-148.

https://doi.org/10.1080/09502380802016246

SITA. 2015. The Passenger IT Trends Survey. Air Transport Industry Insights. In http://www.sita.aero/globalassets/docs/surveys-reports/passenger-it-trends-survey-2015.pdf

Wilkie, Alex. 2014. "Prototyping as Event: Designing the Future of Obesity." Journal of Cultural Economy 7 (4):476-492. https://doi.org/10.1080/17530350.2013.859631

https://www.cntraveler.com/story/this-airport-has-mini-horses-to-helpyou-relax

https://www.iata.org/pressroom/facts figures/Documents/vision2050.pdf

Helene Ilkjaer, Ph.D. The author holds a PhD in Anthropology from the University of Copenhagen (2015) and currently works on an industrial postdoc project co-funded by the Danish Innovation Fund and the Danish start-up company Exruptive A/S. This project focuses on processes of disruptive technology development, methodology and the use of user studies, and airport anthropology. The author's previous areas of research include migration, return migration, diaspora and transnationalism, the anthropology of skills and navigation, gated communities, community building, and philanthropy. The author has conducted extensive fieldwork in Denmark, India and Dubai. 